\title{
Evaluation of Methods to Quantify Populations of Rhizoctonia in Soil
}

\author{
T. N. Spurlock and C. S. Rothrock, Department of Plant Pathology, University of Arkansas, Fayetteville 72701; and W. S. Monfort,
} Department of Plant Pathology, University of Georgia, Coastal Plain Experiment Station, Tifton 31793

\begin{abstract}
Spurlock, T. N., Rothrock, C. S., and Monfort, W. S. 2015. Evaluation of methods to quantify populations of Rhizoctonia in soil. Plant Dis. 99:836-841.

The best method to quantitatively determine populations of Rhizoctonia in soil from soybean fields undergoing rice and soybean rotations was determined for use in a large-scale spatial study to be done over multiple fields and years. The methods evaluated were the toothpick-baiting method, the multiple-pellet soil sampler, and the pour-plate method using elutriated organic matter from soil or surface residue. The toothpickbaiting method was calibrated using the multiple-pellet soil sampler and determined to assay an approximate soil volume of $15.43 \mathrm{~cm}^{3}$. The radius of isolation with the toothpick-baiting technique was approximately $1 \mathrm{~cm}$. In 2009 and 2010, the toothpick method was determined to be the most reliable method for assaying soils, with the most isolates across space and greater recovery of Rhizoctonia solani AG1-IA, R. solani AG11, and $R$. oryzae, the major Rhizoctonia spp. in these fields,

when quantified as propagules per volume of soil or organic matter. In 2011, the recovery of these three groups of Rhizoctonia did not differ statistically when the toothpick-baiting method was compared with the multiple-pellet soil sampler after the volume of soil assayed by the pellet sampler was increased to be similar to that of the toothpick method. However, the labor involved in assaying a similar volume of soil with the multiple-pellet soil sampler was limiting for a large-scale spatial study. The toothpick-baiting method was preferred over the other methods because it was determined to be thorough, inexpensive, nondestructive, and rapid. Additionally, the use of the toothpick-baiting method allows for the determination of the depth of inoculum of isolated fungi for intact soil cores. The mean depth of activity of $R$. solani AG1-IA, $R$. solani AG11, and $R$. oryzae was $1.15,1.55$, and $1.47 \mathrm{~cm}$ respectively.
\end{abstract}

Rhizoctonia refers to an anamorphic genus of fungi that are responsible for substantial diseases on many economically important crops throughout the world. These fungi are grouped according to nuclear condition, species, and anastomosis groups (AG) and subgroups. Rhizoctonia solani AG1-IA is grouped according to demonstrated hyphal fusion with other R. solani in AG 1. It is further divided into the subgroup "IA" based on morphology. This pathogen causes sheath blight in rice and is considered to be the most important pathogen of rice in Arkansas. The fungus also causes aerial blight in soybean. Soybean and rice are used in rotation in many fields in the state. This rotation results in persistent inoculum that causes disease in the following year's crop. $R$. solani AG11 and $R$. oryzae also colonize rice and soybean but they are not considered to be important pathogens of either crop at this time.

Quantifying Rhizoctonia spp. in field soil has been performed many times using methods such as baiting, screening, direct observation, and plating soil $(4,5,10-13,27,30,32)$. In most cases, selective media are used to suppress bacteria and fast-growing fungi, and oomycetes that could limit the ability to properly assess the populations $(6,23,29,31)$. Even with the use of media that suppress microorganisms from soil or organic matter, the methods require saprophytic growth of Rhizoctonia spp. from a bait, soil, or residue, making quantitative recovery difficult.

Direct plating involves the placement of an inoculum source on media. The source can be hyphal fragments, plant debris, sclerotia, a given mass of soil, or surface-disinfested plant material. This method often is secondary to a sampling technique such as baiting or elutriation. In addition, recovery is limited by the workers' ability to identify Rhizoctonia spp. growing onto the medium along with the other microorganisms present. Direct plating of soil using a multiplepellet sampler (11) allows the estimation of propagules of $R$. solani (inoculum) per gram of soil. Soils high in clay content or high in soil organic matter or plant debris may be problematic to create the soil

Corresponding author: T. N. Spurlock; E-mail: tspurlock@uaex.edu

Accepted for publication 3 November 2014.

http://dx.doi.org/10.1094/PDIS-05-14-0446-RE

(C) 2015 The American Phytopathological Society cylinder by the apparatus. The pelleting method does not allow for a determination of what the inoculum source is (hyphal fragment or sclerotium) or the soil fraction in which the inoculum resides (plant debris or in soil pore space).

Elutriation procedures provide a means to separate colonized soil organic matter (5) and sclerotia from soil. This can only be done through destructive sampling. To separate organic material, the samples are placed in a cylinder and combined with water. The samples are softened by the water and separated by agitation. This allows plant material and sclerotia to float and be poured out of the top of the cylinder and into various screens to separate different-sized particles. The material is removed from the screens and suspended in or directly plated on selective medium, and fungal colonies are isolated and transferred to be identified and quantified. The use of nonselective media is tedious and difficult because of the growth of numerous other microorganisms (31). Only a fraction of the recovered material can be assayed but, in theory, this allows for the determination of soil inoculum from sclerotia or colonized soil organic material per a given mass of material or volume of soil.

Baiting can be accomplished using seed (22), plants (12), or toothpicks (24) in a given volume of soil to allow colonization by Rhizoctonia spp. Seed and plants can both be placed into the soil to allow for colonization per a given unit of soil. The procedure is destructive and the unit of soil assayed unclear. The toothpick-baiting method has shown great promise as an inexpensive and rapid assay. This method is nondestructive and entails placing toothpicks vertically in the soil and incubating them for a given time period. The toothpicks are harvested and then directly plated on a selective medium. With all of these recovery techniques, counts estimate inoculum potential, the inoculum's density, and the capacity for saprophytic growth of Rhizoctonia spp. This is unlike dilution-plating techniques, where the spores of an organism are recovered and CFU are determined on appropriate media.

Quantitative polymerase chain reaction (QPCR) techniques also have been used to quantify $R$. solani (2). This method avoids the need for recovery techniques and reliable selective media. Following the use of soil extraction techniques, specific regions of DNA can be amplified in a PCR reaction using specific primers. Primers have been developed for the ribosomal internal transcribed spacer region (rITS) region of many $R$. solani AG and intraspecific groups. An obvious limitation with this technique is the sparse population of $R$. solani, which has been reported to be as low as 2 propagules per $100 \mathrm{~g}$ of 
soil in areas where it can still be responsible for plant disease (32). Given the small amount of soil to be used in the extraction for the QPCR reaction, detection may not be representative of the population for a sampled area. DNA extraction technology from soil has advanced to assay larger samples (20). In addition, this technique only indirectly suggests inoculum potential because inoculum may range from hyphal fragments to large, many-celled sclerotia. It is likely that a large portion of sclerotia in soils where rice and soybean rotation has occurred are not viable (17). Recovery of AG-1 isolates in fallow soil that had originated from rice plants with sheath blight was reported to be reduced by $48 \%$ after 86 days and $100 \%$ after 211 days (1).

The objective of this work was to determine the best methodology to accompany plant sampling in order to quantify populations of Rhizoctonia spp. in fields with a history of rice and soybean rotation while not biasing recovery of species or subspecies of this genus. To allow large-scale spatial sampling (1.6 to 2.4 ha) over multiple fields and years, any method chosen must be fast, utilize minimal labor, and be inexpensive enough to be repeated thousands of times throughout the study.

\section{Materials and Methods}

Toothpick calibration. Aged sclerotia (18 months old) of R. solani AG4 produced on sterile green bean pods were used for the experiments. To produce sclerotia, approximately $100 \mathrm{~g}$ of frozen green bean pods were added to GA-7 tissue culture boxes (Magenta LLC, Chicago) and autoclaved $30 \mathrm{~min}$ on three consecutive days. An isolate of $R$. solani AG4 (isolate PATH) isolated from cotton at the Delta Branch Station near Clarksville, AR, was grown from stock culture on amended potato dextrose agar (PDArad; $18 \mathrm{~g}$ of Difco potato dextrose agar; 10 and $250 \mathrm{mg}$ of the antibiotics rifampicin and ampicillin, respectively; and the miticide fenpropathrin [Danitol 2.4 EC; Valent Chemical Co.] at $0.14 \mathrm{mg}$ a.i./liter). Three 6-mm-diameter PDA disks from the culture were added to the sterile green bean pods and incubated for 2 weeks under ambient light at room temperature. Inoculum was then spread out on cafeteria trays with paper towels underneath the bean pods and dried in a laminar flow hood for approximately 7 to 10 days. Dry bean pods were scraped into a blender (about onethird full) and ground on high for $1 \mathrm{~min}$. Ground material was sieved through number $18(1.00 \mathrm{~mm}), 25(710 \mu \mathrm{m})$, and $50(300 \mu \mathrm{m})$ U.S.A. standard testing sieves (Hogentogler \& Co., Inc., Columbia, MD) stacked on top of each other. The material collected on the number 25 sieve was stored in glass jars and refrigerated.

Natural soil (Stuttgart silt loam) from a field in Stuttgart, AR was collected for use in this experiment. The field had been in a rice and soybean rotation and $R$. solani AG4 was not detected in a preliminary assay. Sclerotia were mixed in dilutions of $0,0.125,0.25,0.5$, and 1 $\mathrm{CFU} / \mathrm{g}$ of soil (equivalent oven dry weight [ODW]). CFU added were determined by plating 100 individual pieces of inoculum in petri dishes filled with Ko and Hora medium (14). The inoculum in the container was shaken to mix sclerotia fragments between harvesting. Those forming colonies were considered viable. Field soil was diluted with the appropriate $\mathrm{CFU}$ based on the percentage of viable propagules. The proper concentration of CFU/g was added to $800 \mathrm{~g}$ of bulk soil (ODW) in plastic bags and mixed thoroughly by hand. After mixing, approximately $616 \mathrm{~g}$ of soil (ODW) was placed in 473-ml Styrofoam cups (Dow Chemical Worldwide) and packed to a bulk density of 1.3 $\mathrm{g} / \mathrm{cm}^{3}$. Five round toothpicks (birch; Diamond) with conical tips were uniformly inserted vertically into each pot at least $2.5 \mathrm{~cm}$ apart to a 5-cm depth and incubated for $48 \mathrm{~h}$. Pots were incubated in a growth chamber at $25^{\circ} \mathrm{C}$ with a 12 -h photoperiod and irrigated with approximately $100 \mathrm{ml}$ of deionized water immediately after placement into the growth chamber. Five replications (pots) of each dilution were arranged in a randomized complete block design and the experiment was conducted twice. After incubation, toothpicks were removed and placed on Ko and Hora medium and incubated at room temperature. Emerging colonies resembling Rhizoctonia spp. were transferred to PDArad by removing the tip of emerging fungal hyphae using a sterile scalpel. Colonies were grouped according to colony morphology of the fungal cultures and the data recorded for amount of toothpick colonization (a possible five 1-cm positions per toothpick).
The remaining soil from each plastic bag was assayed using the multiple-pellet soil sampler (11). Using this method, 15 pellets (294 $\mathrm{mm}^{3} /$ cylinder) were ejected onto a petri dish containing Ko and Hora medium. Ten dishes of pellets were plated for each experimental unit. An extra dish of pellets from each experimental unit was dried at $105^{\circ} \mathrm{C}$ to get an ODW of soil for each group. Dishes were incubated at room temperature and emerging colonies similar to Rhizoctonia spp. were transferred to PDArad. One colony was transferred per pellet. Colonies were grouped according to cultural appearance and the total colonies of $R$. solani AG4 recorded.

The total number of $R$. solani AG4 isolates collected was corrected using a formula for multiple colonization $[\ln (1 / 1-x)]$, where $x$ is the proportion of positive units, to account for multiple units of inoculum colonizing a 1-cm section of a toothpick or soil pellet. The corrected total for the pellet assay was then divided by the total mass of soil assayed (ODW) using the multiple-pellet soil sampler to determine the propagules of $R$. solani AG4 recovered per gram of soil. The total soil assayed by the toothpick method was determined by standardizing the corrected total recovery from the toothpick assay by the recovery per mass of soil assayed by the multiple-pellet soil sampler and then dividing by the corrected total recovery by the soil sampler for each inoculum treatment. The mass of the soil was divided by the bulk density to yield the cubic centimeters of soil assayed by the toothpick and, subsequently, the number of propagules recovered in that volume per treatment. The protocol is summarized in the equation below:

$$
T P V O L=([(T C O R R \times P E L L W T) / P C O R R] / B D) / 5
$$

where $T P V O L$ is the volume assayed by an individual toothpick, TCORR is the corrected total of recovery by all toothpicks, PELLWT is the ODW of all pellets, PCORR is the corrected total recovery of all pellets, and $B D$ is the bulk density of the soil in which the experiment was done. The product is divided by 5 to give the volume of an individual toothpick.

Field sampling procedure. Forty-eight field positions were mapped using a Trimble GeoXT GPS unit and Geobeacon (Trimble Navigation Limited, Sunnyvale, CA) on 10 April 2009 in a field near Stuttgart, AR. The positions were selected to represent the slope of the field with a pair of points in a row to be positioned intermittent of the previous season's rice levees, with three rows of sampling points. Sampling was performed on GPS positions on 10 April 2009 and 14 April 2010, and rice and soybean, respectively, were produced the previous season. The positions were located after the initial sampling using Trac-Mate software (Farm Works Information Management, Hamilton, IN) within the Windows Mobile 6.0 operating system (Microsoft Corp., Redlands, WA) operating on a Trimble Nomad 6GB (Trimble Navigation Limited). Sampling consisted of removing intact sections of crop residue and soil from each position using a turfgrass sod-cutter (Bluebird SC550, $46 \mathrm{~cm}$; Bluebird, Charlotte, NC) at a $6.5-\mathrm{cm}$ depth and placing the samples into 91-by-46-cm plastic tubs. Surface residue and soil of each sample was not disturbed. Lids were placed on tubs and samples were transported back to the laboratory in Fayetteville, AR and stored at room temperature with the lids on to retain soil moisture $\left(22^{\circ} \mathrm{C}\right)$. All assays were completed within 2 weeks from the time of sampling. In 2009, the selective medium used was Ko and Hora. In 2010, two media were used for each assay: Ko and Hora medium and a newly developed selective medium, TS1 (28). Each assay was performed simultaneously for both media.

Toothpick baiting. Fifteen toothpicks were placed vertically in the soil to a depth of $5 \mathrm{~cm}$ and incubated at room temperature for $48 \mathrm{~h}$ for each tub. Toothpicks were arbitrarily placed in the soil no closer than $5 \mathrm{~cm}$ to each other. Toothpicks were then removed and placed on selective medium in 100-mm-diameter petri dishes, three toothpicks per dish. From 12 to $48 \mathrm{~h}$ after plating, fungal colonies resembling Rhizoctonia spp. were marked and transferred to PDArad. The specific depth $(0$ to $5 \mathrm{~cm}$ ) of hyphal emergence from the toothpick was recorded by placing the petri dish over a $5-\mathrm{cm}$ template.

Residue plating. The depth of the rice residue was measured three times at arbitrary locations in each tub containing intact soil samples in 2009. The residue was then removed from the surface of the intact samples from each tub immediately after the toothpick assay and 
refrigerated in separate plastic bags. Samples were removed from storage and mixed, and a mean of $1.25 \mathrm{~g}$ of residue was removed from each sample and cut with sterilized scissors into 1-cm-long sections. The chopped sample was then mixed with molten Ko and Hora medium and swirled for about $10 \mathrm{~s}$ and poured into 8 to 10 petri dishes. Concentration of dry material in the molten media was determined by visual inspection of particle density in the petri dishes. Samples were incubated at room temperature for approximately 14 to $16 \mathrm{~h}$ before marking and transferring all colonies that appeared to be Rhizoctonia spp. onto PDArad. Petri dishes were visually inspected again $24 \mathrm{~h}$ later and additional transfers to PDArad were made if needed.

Elutriation. Bulk soil samples were removed from the stored intact samples from each tub by cutting an approximately $500-\mathrm{cm}^{3}$ block of soil from the center of the bulk soil in the tubs after residue removal and placed into individual plastic bags marked by tub. The soil was removed from the plastic bags and eluted in a semiautomatic elutriator (3). Elutriator settings were set to an eight-min cycle at $40 \mathrm{psi}$ agitation using a number $140(106-\mu \mathrm{m})$ U.S.A. standard testing sieve. These samples were then placed in plastic bags and stored overnight at 2 to $5^{\circ} \mathrm{C}$. Representative samples were taken from the eluted material and dried at $60^{\circ} \mathrm{C}$ for $48 \mathrm{~h}$ to estimate moisture content across all samples. A mean of $1.308 \mathrm{~g}$ (standard deviation $[\mathrm{SD}] \pm$ 0.15 ) dry weight equivalent was mixed with approximately $250 \mathrm{ml}$ of molten selective medium and poured into 10 to 15 petri dishes. Samples were incubated at room temperature for approximately 14 to $16 \mathrm{~h}$ before marking and transferring all colonies that appeared to be Rhizoctonia spp. onto PDArad. Petri dishes were visually inspected a second time, $24 \mathrm{~h}$ later, and additional transfers were made if necessary. In 2010, the mean mass of eluted residue was $1.187 \mathrm{~g}$ (SD \pm $0.15)$ dry weight.

Pelleting. After removal of bulk soil for the elutriation procedure, a multiple-pellet soil sampler was used to make 150 pellets/sample. In total, 15 soil pellets were ejected on selective medium in each of 10 petri dishes for each sample and incubated overnight at room temperature. After $12 \mathrm{~h}$ of incubation, colonies resembling Rhizoctonia spp. were marked and transferred into petri dishes filled with PDArad. Petri dishes were visually inspected again $24 \mathrm{~h}$ later and additional transfers made if needed. An additional set of 15 pellets was collected for each sample to determine the pellet ODW.

In 2011, 20 GPS positions, 10 per field, were arbitrarily chosen in two fields for methods comparison. One field was the same field near Stuttgart, AR and the other field was located near Hazen, AR. For each position, five intact soil cores, approximately $300 \mathrm{~cm}^{3}$ of soil per core, were taken using a Bulb Hound bulb planter (Hound Dog Products, Inc., Edna, MN) and placed in 473-ml Styrofoam cups and transported back to the laboratory in Fayetteville, AR. The bottom of each cup was punctured with one hole that was approximately $2 \mathrm{~mm}$ in diameter. Cups were irrigated from the bottom to bring soil to close to saturation and allowed to drain for $12 \mathrm{~h}$. Toothpicks were then placed in each soil core, 6 per core, and incubated for $48 \mathrm{~h}$, as mentioned previously. After toothpick removal, the soil from all cups for a position was placed in a plastic bag and mixed. After mixing, a portion was poured into clean plastic trays and assayed using the multiple-pellet soil sampler. The plastic bags of soil were then eluted individually as previously described. A mean subsample of $1.38 \mathrm{~g}$ $(\mathrm{SD} \pm 0.28)$ dry weight of material was collected from the eluted residue and assayed. The toothpick, pellet, and eluted residue were incubated on the TS1 medium and isolates collected as previously described. The GPS positions were treated as a completely randomized design for each field.

Isolate collection and identification. Isolates of Rhizoctonia spp. in pure culture grown on PDArad were grouped by cultural appearance and counted by position and method. Isolate nomenclature included field, GPS position, method, and petri dish number (plus toothpick number and depth of recovery for isolates acquired from toothpickbaiting assays). Isolates morphologically similar to $R$. solani were subjected to anastomosis reactions with testers of known identity $(15,19)$. After anastomosis reaction, 12 isolates representing the three major groups ( $R$. solani AG1-IA and AG11 and $R$. oryzae) were arbitrarily selected to confirm identity of the group by amplification of the rDNA ITS1 and ITS4.

DNA extraction, amplification, and sequencing. Actively growing fungal hyphae were harvested with a sterilized scalpel and placed in 2-ml microtubes from fungi growing in petri dishes with solidified PDA. DNA was extracted using a salting-out procedure with inhouse reagents (26). PCR was conducted using the primers ITS1 (CC GTA GGT GAA CCT TGC GG) and ITS4 (TCC TCC GCT TAT TGA TAT GC) (33). These primers amplify the $3^{\prime}$ end of the 18S rRNA gene, ITS1, 5.8S rRNA, ITS2, and a $5^{\prime}$ region of the $28 \mathrm{~S}$ rRNA gene. The thermal cycler profile consisted of 40 cycles of $94^{\circ} \mathrm{C}$ for $45 \mathrm{~s}, 53^{\circ} \mathrm{C}$ for $60 \mathrm{~s}$, and $72^{\circ} \mathrm{C}$ for $60 \mathrm{~s}$. PCR products were subjected to electrophoresis in $2 \%$ agarose gels, and PCR products were visualized under UV light (BioDocit Imaging System, UVP, LLC, Upland, CA). Amplified DNA samples were purified, concentrated with PES 30k filter devices (VWR, Radnor, PA), and sent for direct sequencing in both directions (University of Arkansas Medical School, Little Rock). DNA sequences were aligned using BioEdit v5.89 (9) and adjusted manually.

Statistical analysis. For the comparison of volumes estimated for the toothpick-baiting method using four rates of $R$. solani AG4 inoculum, data were analyzed using PROC MIXED in SAS 9.4 (SAS Institute, Cary, NC), with means of fixed effects separated using Fisher's protected least significant difference (LSD) and blocks random. After standardization of the toothpick-baiting method, all populations were represented as volume of the appropriate substrate by dry weight. For comparisons of methods in 2009 and 2010, populations were compared using descriptive statistics (mean, SD, and coefficient of variation) and the number of points positive for recovery (from a possible 48) recorded and reported as "hits". For methods comparisons in 2011, data were analyzed using PROC MIXED in SAS 9.2 and means of fixed effects separated using Fisher's protected LSD.

\section{Results}

The recovery of $R$. solani AG4 using the soil-pellet assay was used to calculate the volume of soil assayed by the toothpick-baiting method. A soil volume of $15.43 \mathrm{~cm}^{3}$ at a bulk density of $1.3 \mathrm{~g} / \mathrm{cm}^{3}$ was assayed per toothpick based on a recovery equivalent to the multiple-pellet soil sampler. This equates to a radius of approximately $1 \mathrm{~cm}$ from the outside edge of the toothpick given the following formula:

$$
r=\sqrt[2]{(T P V O L} /[(\pi h 1)+(1 / 3 \pi h 2)])
$$

where $r$ is the radius of the toothpick and TPVOL is toothpick volume and is divided by the volume of a cylinder with a height $(h 1)$ of $4 \mathrm{~cm}$ and a cone with a height $(h 2)$ of $1 \mathrm{~cm}$. The volume of soil assayed for the four soil inoculum potentials of $R$. solani AG4 recovered was $12.83,19.0,17.2$, and $12.7 \mathrm{~cm}^{3}$ for populations of $0.125,0.25,0.5$, and 1.0 propagules/g of soil, respectively, and did not differ significantly among infestation levels $(P=0.19)$.

The three predominant groups of Rhizoctonia recovered in 2009, 2010 , and 2011 were $R$. solani AG1-IA, $R$. solani AG11, and $R$. oryzae. The total population of Rhizoctonia spp. across years was 152 isolates (multiple-soil pellet method), 78 isolates (residue plating, 2009 only), 12 isolates (elutriation), and 452 isolates (toothpickbaiting method). Overall, the toothpick-baiting method yielded the greatest and most consistent recovery of these isolates in 2009 (Table 1) and 2010 (Table 2). The populations of Rhizoctonia spp. did not include $R$. solani AG1-IA from the multiple-soil pellet method or elutriation in 2009. No isolates from the three predominant Rhizoctonia groups were recovered in 2010 using the elutriation method on Ko and Hora medium. A newly developed medium (TS1) provided better suppression of Trichoderma spp. and allowed for detection of $R$. solani for elutriation. However, the recovery of Rhizoctonia spp. from elutriation was not more consistent than the toothpick-baiting method even with improved media performance. Due to a change in tillage practices by the farmer, there was no surface residue available in 2010 for assay. 
In 2011, the multiple-pellet soil, toothpick-baiting, and elutriation methods were compared using only the TS 1 medium for 20 positions in each of two fields. The elutriation yielded the most inconsistent recovery, with $R$. solani AG11 isolated at only 6 of 20 positions, $R$. solani AG1-IA not recovered, and $R$. oryzae recovered from only two positions (data not shown). Given this inconsistency, the elutriation method was omitted from the analysis. The methodology for

Table 1. Comparison of recovery of the predominant Rhizoctonia spp. using three methods from 48 positions in a field near Stuttgart, AR sampled in April 2009

\begin{tabular}{|c|c|c|c|}
\hline Rhizoctonia spp. ${ }^{\mathrm{v}}$ & Pellet $^{w}$ & Residue $^{x}$ & Toothpick $^{\mathbf{y}}$ \\
\hline \multicolumn{4}{|l|}{ Rhizoctonia solani AG11 } \\
\hline Total & 99 & 53 & 175 \\
\hline Mean & 12.51 & 0.09 & 7.88 \\
\hline SD & 18.95 & 0.25 & 12.83 \\
\hline $\mathrm{CV}$ & 1.51 & 2.65 & 1.63 \\
\hline Hits & 27 & 15 & 22 \\
\hline \multicolumn{4}{|l|}{ R. solani AG1-IA } \\
\hline Total & 0 & 6 & 72 \\
\hline Mean & 0 & 0.01 & 3.24 \\
\hline SD & 0 & 0.04 & 5.25 \\
\hline $\mathrm{CV}$ & 0 & 3.89 & 1.62 \\
\hline Hits & 0 & 4 & 27 \\
\hline \multicolumn{4}{|l|}{ R. oryzae } \\
\hline Total & 23 & 19 & 74 \\
\hline Mean & 2.91 & 0.03 & 3.33 \\
\hline SD & 4.15 & 0.07 & 3.98 \\
\hline $\mathrm{CV}$ & 1.43 & 2.13 & 1.19 \\
\hline Hits & 18 & 11 & 28 \\
\hline Substrate sampled $\left(\mathrm{cm}^{3}\right)^{\mathrm{z}}$ & 3,956 & 278,932 & 11,110 \\
\hline
\end{tabular}

$\mathrm{v}$ Total $=$ total isolates recovered, Mean $=$ mean recovery across all 48 points expressed as propagules $/ 500 \mathrm{~cm}^{3}$ of substrate, $\mathrm{SD}=$ standard deviation, $\mathrm{CV}=$ coefficient of variation, and Hits = total number of positions where at least one Rhizoctonia isolate for the group was recovered.

${ }^{w}$ Multiple-pellet soil sampler technique.

x Pour-plate assay of surface residue recovered.

y Modified toothpick-baiting method.

$\mathrm{z}$ Total volume of substrate sampled for each method. the multiple-pellet soil sampler method had been modified to include more soil assayed per position. The amount of soil assayed in 2011 per sample position was increased to approximately 412 compared with 82 and $165 \mathrm{~cm}^{3}\left(82.4 \mathrm{~cm}^{3}\right.$ per medium) per sample point in 2009 and 2010, respectively. The increase in volume resulted in the per-point comparison for the toothpick-baiting method and the multiple-pellet soil sampler method being similar, in that the 30 toothpicks/point assayed an estimated volume of $462.9 \mathrm{~cm}^{3}$. This resulted in more consistent recovery per sample point of $R$. solani AG11 and AG1-IA and $R$. oryzae than in previous years. The toothpick-baiting method and the multiple-pellet soil sampler did not differ as a sampling method for Hazen $(P=0.45)$ or Stuttgart $(P=0.34)$ (Table 3$)$. Recovery of AG11 was greater at Hazen than $R$. oryzae or $R$. solani AG1-IA (Table 3). For Stuttgart, recovery of Rhizoctonia spp. was not significantly different (Table 3$)$. There was no interaction between method and Rhizoctonia spp. recovery for Hazen $(P=0.37)$ or Stuttgart $(P=$ $0.94)$, suggesting that recovery of groups was consistent across methods compared.

The toothpick-baiting method also allowed for the estimation of the depth of inoculum placement by the recovered Rhizoctonia spp. Across all years, the mean of depths recorded was between 0.81 and $2.34 \mathrm{~cm}$ for Rhizoctonia spp. (Table 4).

\section{Discussion}

The results from 2 years of field evaluation demonstrated that the toothpick-baiting method was the most efficient for recovery of Rhizoctonia spp. from soil in fields undergoing rice and soybean rotation. For intact soil cores, this method also allows for the collection of the approximate depth of inoculum of Rhizoctonia spp. In theory, soil samples do not have to be collected and brought back to the laboratory. A field could be assayed by simply placing the toothpicks in the field at a number of points and then recovering them after the 48-h incubation period to minimize the effects of storage and transportation on a biological system and further reduce costs of storage and transportation of soil samples. However, soil water matric potential may affect recovery.

The toothpick-baiting method has been shown to be an effective means for the recovery and isolation of $R$. solani previously. Kumar et al. (16) used toothpicks to assess the growth of $R$. solani AG11 and AG8, pathogens of lupin in Australia, in various soil conditions. Gill

Table 2. Comparison of recovery of the predominant Rhizoctonia spp. using three methods from 48 positions in a field near Stuttgart, AR sampled in April 2010

\begin{tabular}{|c|c|c|c|c|c|c|}
\hline \multirow[b]{2}{*}{ Rhizoctonia spp. ${ }^{\mathrm{v}}$} & \multicolumn{3}{|c|}{ Ko and Hora } & \multicolumn{3}{|c|}{ TS1 } \\
\hline & Pellet $^{w}$ & Elutriation $^{\mathrm{x}}$ & Toothpick $^{\mathbf{y}}$ & Pellet $^{w}$ & Elutriation $^{\mathrm{x}}$ & Toothpick $^{\mathbf{y}}$ \\
\hline \multicolumn{7}{|l|}{ Rhizoctonia solani AG11 } \\
\hline Total & 4 & 0 & 32 & 16 & 11 & 58 \\
\hline Mean & 0.51 & 0 & 1.44 & 2.02 & 0.26 & 2.61 \\
\hline SD & 1.69 & 0 & 2.28 & 7.23 & 0.54 & 3.02 \\
\hline $\mathrm{CV}$ & 3.35 & 0 & 1.62 & 3.57 & 2.07 & 1.16 \\
\hline Hits & 5 & 0 & 18 & 9 & 10 & 26 \\
\hline \multicolumn{7}{|l|}{ R. solani AG1-IA } \\
\hline Total & 0 & 0 & 9 & 2 & 1 & 11 \\
\hline Mean & 0 & 0 & 0.41 & 0.25 & 0.02 & 0.49 \\
\hline SD & 0 & 0 & 1.15 & 1.23 & 0.16 & 1.19 \\
\hline $\mathrm{CV}$ & 0 & 0 & 2.80 & 4.84 & 6.96 & 2.42 \\
\hline Hits & 0 & 0 & 6 & 2 & 1 & 8 \\
\hline \multicolumn{7}{|l|}{ R. oryzae } \\
\hline Total & 0 & 0 & 5 & 8 & 0 & 11 \\
\hline Mean & 0 & 0 & 0.23 & 1.01 & 0 & 0.49 \\
\hline SD & 0 & 0 & 1.02 & 2.28 & 0 & 1.62 \\
\hline $\mathrm{CV}$ & 0 & 0 & 4.43 & 2.26 & 0 & 3.30 \\
\hline Hits & 0 & 0 & 3 & 8 & 0 & 6 \\
\hline Substrate sampled $\left(\mathrm{cm}^{3}\right)^{\mathrm{z}}$ & 3956 & 210582 & 11110 & 3956 & 210582 & 11110 \\
\hline
\end{tabular}

$\vee$ Total $=$ total isolates recovered, Mean $=$ mean recovery across all 48 points expressed as propagules $/ 500 \mathrm{~cm}{ }^{3}$ of substrate, $\mathrm{SD}=\mathrm{standard}$ deviation, $\mathrm{CV}=$ coefficient of variation, and Hits = total number of positions where at least one Rhizoctonia isolate for the group was recovered.

${ }^{w}$ Multiple-pellet soil sampler technique.

x Pour-plate assay of surface residue recovered.

y Modified toothpick-baiting method.

$\mathrm{z}$ The total volume of substrate sampled for each method. 
et al. (7) used toothpicks to assess the spread of $R$. solani AG8 causing root rot of wheat in soil. Paulitz et al. (25) also used the toothpickbaiting method to isolate $R$. solani AG8 and $R$. oryzae from field soil. Pannecoucque et al. (21) isolated $R$. solani isolates representing multiple AG from a cauliflower field in Belgium. Paulitz reported that there was a demonstrated linear relationship between the quantities of $R$. solani AG8 or $R$. oryzae recovered from toothpick baiting and the amount of inoculum applied to the field soil assayed. Isolates of Rhizoctonia spp. that attached to the toothpick and grew in culture were counted and standardized per the volume of soil the toothpicks displaced. At a bulk density of $1 \mathrm{~g} / \mathrm{cm}^{3}$, five toothpicks assay $0.375 \mathrm{~g}$ or $0.375 \mathrm{~cm}^{3}$, the actual soil volume displaced. The results from the artificially infested soil containing its natural microflora using aged sclerotia suggest that, when compared with another quantitative technique, soil pelleting, the volume sampled by the toothpick is much greater than the soil volume displaced by the toothpick. Based on calculation of recovery, the radius of soil allowing baiting of the pathogen was about $1 \mathrm{~cm}$ to make the two quantitative methods comparable.

The multiple-pellet soil sampler also was determined to be a reliable method of assessing soil inoculum potential in the field across years. To be useful, an extensive amount of sampling must be done. Given the labor involved in a large-scale spatial project, it is not a preferred method over the toothpick-baiting procedure. However, over a smaller area, if the sampling was extensive enough, this method should provide a relatively precise representation of a given population. Furthermore, the multiple-pellet soil sampler does not allow for an assay deeper than the cylinder could provide using intact soil samples.

In 2010, the surface residue could not be assayed because tillage practices differed for the field when planted in rice, and all soybean residues had been buried prior to the field being available for sampling. Using surface residue in 2009 was more effective for isolation of Rhizoctonia spp. than the soil elutriation procedure, even though these assays utilized a similar pour-plate methodology. The laborious nature of both of these methodologies limits their value for large sample numbers. However, in theory, there is a clear value in the ability to assay residue that has been removed from the soil profile or that

Table 3. Rhizoctonia spp. recovered for two fields near Hazen, AR and Stuttgart, AR in 2011 using the multiple-pellet soil sampler and the toothpickbaiting method

\begin{tabular}{llc}
\hline & \multicolumn{2}{c}{ Propagules/500 $\mathbf{~ c m}^{\mathbf{3}}$ of soil } \\
\cline { 2 - 3 } Parameter & Hazen & Stuttgart \\
\hline Rhizoctonia spp. & & \\
$\quad$ Rhizoctonia solani AG11 & $3.21 \mathrm{a}$ & $0.28 \mathrm{a}$ \\
R. oryzae & $0.71 \mathrm{~b}$ & $0.42 \mathrm{a}$ \\
R. solani AG1-IA & $0.18 \mathrm{~b}$ & $0.74 \mathrm{a}$ \\
LSD & 0.92 & 0.46 \\
Method & & \\
$\quad$ Toothpick baiting & $1.11 \mathrm{a}$ & $0.39 \mathrm{a}$ \\
Multiple-pellet soil sampler & $1.61 \mathrm{a}$ & $0.57 \mathrm{a}$ \\
LSD & 0.75 & 0.41 \\
\hline
\end{tabular}

${ }^{\mathrm{z}}$ Means followed by the same letter in a column and parameter are not significantly different using Fisher's protected least significant difference $(\mathrm{LSD} ; P=0.05)$.

Table 4. Depth of recovery $(\mathrm{cm})$ of Rhizoctonia spp. using the toothpickbaiting method across 3 years ${ }^{2}$

\begin{tabular}{|c|c|c|c|c|c|c|}
\hline \multirow[b]{2}{*}{ Year } & \multicolumn{2}{|c|}{$\begin{array}{c}\text { Rhizoctonia solani } \\
\text { AG1-IA }\end{array}$} & \multicolumn{2}{|c|}{ R. solani AG11 } & \multicolumn{2}{|c|}{ R. oryzae } \\
\hline & Mean $(\mathrm{cm})$ & SD & Mean (cm) & SD & Mean $(\mathrm{cm})$ & SD \\
\hline 2009 & 1.53 & 0.82 & 1.50 & 0.89 & 1.53 & 0.86 \\
\hline 2010 & 0.85 & 0.48 & 0.81 & 0.47 & 0.88 & 0.50 \\
\hline 2011 & 1.07 & 0.98 & 2.34 & 1.39 & 2.00 & 1.73 \\
\hline
\end{tabular}

${ }^{\mathrm{z}}$ Values expressed as mean of measured toothpick zone (five 1-cm zones), with the midpoint of each zone analyzed. The range of possible depths was 0 to $5 \mathrm{~cm} . \mathrm{SD}=$ standard deviation. has been collected from the soil surface to evaluate inoculum source, sclerotia, or hyphae associated with residue. The small amount of residue that can be assayed in petri dishes becomes problematic when dealing with a fungus such as $R$. solani that can cause disease at low populations. The accuracy of quantifying populations by position from the elutriation procedure was complicated by the abundance of Trichoderma spp. and other fungi that colonize residue. Fungi within the genus Trichoderma grow rapidly and many are antagonistic to Rhizoctonia spp. (18). The abundance of these organisms in the petri dishes from the eluted residue was much greater than in the petri dishes from the surface residue, indicating that dealing with surface residue in a pour-plate experiment may be accomplished more easily with a selective medium than residue that had been buried for any length of time. Even with an improved selective medium in 2010, the elutriation methodology was vastly inferior to the toothpick-baiting method.

Spatial variability of $R$. solani has been demonstrated previously $(8,25)$. This variability likely relies on a number of factors that require extensive spatial sampling to examine factors influencing inoculum dispersal or survival. Given the inexpensive nature of the toothpick-baiting method, a large-scale spatial assay of populations within fields is affordable. In time, when technology improves and the cost of QPCR decreases, these two methods may be utilized to assay the same area throughout time and space and test hypotheses involving DNA quantity and inoculum potential. The toothpickbaiting method described in this study allowed for a large-scale spatial study to determine distribution and relationships of Rhizoctonia spp. with disease in soybean fields rotated with rice. This sampling technique was optimized to allow fields to be assayed to determine population diversity, quantity, and the potential impact of Rhizoctonia spp. on crop performance. Use of the toothpick-baiting method to determine population distribution may require site-specific calibration, as outlined in this work. However, its simplicity as a mechanism for detection and low cost allow for a repetitive assay technique for farmer's fields, gardens, or other soils of interest.

\section{Acknowledgments}

We thank A. Szalanski, Professor of Entomology, University of Arkansas, Fayetteville and L. Chapman, Instructor of Mathematics, University of Arkansas, Monticello for editing portions of this work.

\section{Literature Cited}

1. Bell, D. K., and Sumner, D. R. 1987. Survival of Rhizoctonia solani and other soilborne basidiomycetes in fallow soil. Plant Dis. 71:911-915.

2. Budge, G. E., Pietravalle, S., Boonham, N., Shaw, M. W., and Colyer, A. 2009. Molecular tools to investigate Rhizoctonia solani distribution in soil. Plant Pathol. 58:1071-1080.

3. Byrd, D. W., Jr., Griffin, W. E., Small, R. H., Stone, C. A., Barker, K. R., Ferris, H., and Nusbaum, C. J. 1976. Two semi-automatic elutriators for extracting nematodes and certain fungi from soil. J. Nematol. 8:206-212.

4. Castro, C., Davis, J. R., and Wiese, M. V. 1988. Quantitative estimation of Rhizoctonia solani AG-3 in soil. Phytopathology 78:1287-1292.

5. Clark, C. A., Sasser, J. N., and Barker, K. R. 1978. Elutriation procedures for quantitative assay of soils for Rhizoctonia solani. Phytopathology 68 1234-1236.

6. Gangopadhyay S., and Grover R. K. 1985. A selective medium for isolating Rhizoctonia solani from soil. Ann. Appl. Biol. 106:405-412.

7. Gill, J. S., Sivasithamparam, K., and Smettem, K. R. J. 2000. Soil types with different texture affects development of Rhizoctonia root rot of wheat seedlings. Plant Soil 221:113-120.

8. Gilligan, C. A., Simons, S. A., and Hide, G. A. 1996. Inoculum density and spatial pattern of Rhizoctonia solani in field plots of Solanum tuberosum Effects of cropping frequency. Plant Pathol. 45:232-244.

9. Hall, T. A. 1999. Bioedit: A user-friendly biological sequence alignment editor and analysis program for Windows 95/98/NT. Acids Symp. Ser. 41:95-98.

10. Harris, K., Young, I. M., Gilligan, C. A., Otten, W., and Ritz, K. 2003. Effect of bulk density on the spatial organisation of the fungus Rhizoctonia solani in soil. FEMS Microbiol. Ecol. 44:45-56.

11. Henis, Y., Ghaffar, A., Baker, R., and Gillespie, S. L. 1978. A new pellet soil sampler and its use for the study of population dynamics of Rhizoctonia solan in soil. Phytopathology 68:371-376.

12. Huang, J. W., and Kuhlman, E. G. 1989. Recovery and pathogenicity of Rhizoctonia solani and binucleate Rhizoctonia-like fungi in forest nurseries. Plant Dis. 73:968-972.

13. Hyakumachi, M., and Ui, T. 1984. Comparison of soil-pellet and sievingfloatation methods for enumeration of sugarbeet-root-rot fungus (Rhizoctonia 
solani AG 2-2). Nihon Shokubutsu Byori Gakkaiho =. Ann. Phytopathological Soc. Jpn. 50:551-553.

14. Ko, W. H., and Hora, F. K. 1971. A selective medium for the quantitative determination of Rhizoctonia solani in soil. Phytopathology 61:707-710.

15. Kronland, W. C., and Stanghellini, M. E. 1988. Clean slide technique for the observation of anastomosis and nuclear condition of Rhizoctonia solani. Phytopathology 78:820-822.

16. Kumar, S., Sivasithamparam, K., Gill, J. S., and Sweetingham, M. W. 1999. Temperature and water potential effects on growth and pathogenicity of Rhizoctonia solani AG-11 to lupin. Can. J. Microbiol. 45:389-395.

17. Lee, F. N. 1980. Number, viability, and buoyancy of Rhizoctonia solani sclerotia in Arkansas rice fields. Plant Dis. 64:298-300.

18. Lewis, J. A., and Papavizas, G. C. 1985. Effect of mycelial preparations of Trichoderma and Gliocladium on populations of Rhizoctonia solani and the incidence of damping-off. Phytopathology 75:812-817.

19. MacNish, G. C., Brainard, K. A., and Carling, D. E. 1993. Characterization of Rhizoctonia solani AG-8 from bare patches by pectic isozyme (Zymogram) and anastomosis techniques. Phytopathology 83:922-927.

20. Ophel-Keller, K., McKay, A., Hartley, D., Herdina, and Curran, J. 2008. Development of a routine DNA-based testing service for soilborne diseases in Australia. [electronic resource] Australas. Plant Pathol. 37:243-253.

21. Pannecoucque, J., Van Beneden, S., and Hofte, M. 2008. Characterization and pathogenicity of Rhizoctonia isolates associated with cauliflower in Belgium. Plant Pathol. 57:737-746.

22. Papavizas, G. C., Adams, P. B., Lumsden, R. D., Lewis, J. A., Dow, R. L., Ayers, W. A., and Kantzes, J. G. 1975. Ecology and epidemiology of Rhizoctonia solani in field soil. Phytopathology 65:871-877.
23. Paulitz, T. C. 2002. First report of Rhizoctonia oryzae on pea. Plant Dis. $86: 442$.

24. Paulitz, T. C., and Schroeder, K. L. 2005. A new method for the quantification of Rhizoctonia solani and R. oryzae from soil. Plant Dis. 89:767-772.

25. Paulitz, T. C., Zhang, H., and Cook, R. J. 2003. Spatial distribution of Rhizoctonia solani and Rhizoctonia oryzae and at three different scales in direct-seeded wheat. Can. J. Plant Pathol. 26:419.

26. Sambrook, J., and Russell, D. W. 2001. Molecular Cloning. Cold Spring Harbor Laboratory Press, Cold Spring Harbor, NY.

27. Sneh, B., Katan, J., Henis, Y., and Wahl, I. 1966. Methods for evaluating inoculum density of Rhizoctonia in naturally infested soil. Phytopathology 56 74-78.

28. Spurlock, T., Rothrock, C., and Monfort, W. 2011. A new selective medium for isolation of Rhizoctonia spp. from soil. Phytopathology 101:S170.

29. Trujillo, E. E., Cavin, C. A., Aragaki, M., and Yoshimura, M. A. 1987. Ethanol-potassium nitrate medium for enumerating Rhizoctonia solani-like fungi from soil. Plant Dis. 71:1098-1100.

30. Van Bruggen, A. H. C., and Arneson, P. A. 1986. Quantitative recovery of Rhizoctonia solani from soil. Plant Dis. 70:320-323.

31. Vincelli, P. C., and Beaupré, C. M. S. 1989. Comparison of media for isolating Rhizoctonia solani from soil. Plant Dis. 73:1014-1017.

32. Weinhold, A. R. 1977. Population of Rhizoctonia solani in agricultural soils determined by a screening procedure. Phytopathology 67:566-569.

33. White, T. J., Bruns, T., Lee, S., and Taylor, J. W. 1990. Amplification and direct sequencing of fungal ribosomal RNA genes for phylogenetics. Pages 315-322 in: PCR Protocols: A Guide to Methods and Applications. Academic Press Inc., New York. 